\title{
O paradigma do Direito Fraterno frente ao fenômeno migratório
}

\author{
El paradigma del Derecho Fraterno frente al fenómeno migratório \\ The paradigm of the Fraternal Law in the face of the migratory \\ phenomenon
}

Felippe Velasques Giriboni ${ }^{1}$

Deisemara Turatti Langoski ${ }^{2}$

\begin{abstract}
Resumo
A Venezuela atualmente passa por uma enorme crise socioeconômica e política que por consequência levou milhares de pessoas a deixarem seu país natal em busca de uma melhor qualidade de vida, devido ao desemprego, a falta de produtos básicos, como alimentação e serviços públicos essenciais, como a saúde. O objetivo deste trabalho consiste em verificar se a política pública de acolhimento dos venezuelanos no estado do Rio Grande do Sul pode ser analisado sob a teoria do direito fraterno. Para fins metodológicos utiliza-se o método de abordagem dedutivo e o tipo de pesquisa bibliográfico. A Carta Magna de 1988, em seu preâmbulo apresenta "a igualdade e justiça como o valor supremo de uma sociedade fraterna, pluralista e sem preconceitos", desígnios almejados pelos constituintes para o Estado Democrático de Direito. A obra "O Direito Fraterno" de Eligio Resta destaca que esse direto vive da falta de fundamentos, pois a verdade que o move é um direito inclusivo, que promove o acesso a bens e direitos fundamentais aposta na existência de um bem comum. A finalidade da ação de acolhimento aos imigrantes, medida paliativa do Governo Federal, que apenas o estado do RS recebeu aproximadamente 602 venezuelanos para o abrigamento compactua com essa visão. Em parceria com o ACNUR os venezuelanos recebem moradia, alimentação e atendimento de serviços básicos. Percebem-se iniciativas que podem ser concluídas como práxis do Direito Fraterno; notório que ainda há muito a ser realizado.
\end{abstract}

Palavras-Chave: direito fraterno; políticas migratórias; acolhimento; venezuelanos.

\section{Resumen}

Venezuela actualmente pasa por una enorme crisis socioeconómica y política que por consiguiente ha llevado a miles de personas a abandonar su país natal en busca de una mejor calidad de vida, debido al desempleo, la falta de productos básicos, como la alimentación y los servicios públicos esenciales, la salud. El objetivo de este trabajo consiste en verificar si la política pública de acogida de los venezolanos en el estado de Rio Grande do Sul puede ser analizada bajo la teoría del derecho fraterno. Para fines metodológicos se utiliza el método de abordaje deductivo y el tipo de investigación bibliográfica. La Carta Magna de 1988, en su preámbulo, presenta "la igualdad y la justicia como el valor supremo de una sociedad fraterna, pluralista y sin prejuicios", designios anhelados por los constituyentes para el Estado Democrático de Derecho. La obra "El Derecho Fraterno" de Eligio queda destaca que ese directo vive de la falta de fundamentos, pues la verdad que lo mueve es un derecho inclusivo, que promueve el acceso a bienes y derechos fundamentales apuesta por la existencia de un bien común. La finalidad de la acción de acogida a los inmigrantes, medida paliativa del Gobierno Federal, que sólo el estado del RS recibió aproximadamente 602 venezolanos para el refugio compacto con esa visión. En asociación con el ACNUR los venezolanos reciben vivienda, alimentación y atención de servicios básicos. Se percibe iniciativas que pueden ser concluidas como praxis del Derecho Fraterno; que no hay mucho que hacer.

Palabras claves: derecho fraterno; políticas públicas; recepción; venezolanos;

${ }^{1}$ Graduando em Direito, Universidade Federal do Pampa, Santana do Livramento, RS, Brasil; felippe.velasques@gmail.com.

${ }^{2}$ Doutora em Direito UFSC, Santana do Livramento, RS, Brasil; deisemaraturatti@ unipampa.edu.br. 


\begin{abstract}
Venezuela is currently experiencing a huge socioeconomic and political crisis that has led thousands of people to leave their native country in search of a better quality of life due to unemployment, lack of basic products such as food and essential public services, such as the health. The purpose of this paper is to verify if the public policy of reception of Venezuelans in the state of Rio Grande do Sul can be analyzed under the theory of fraternal law. For methodological purposes the method of deductive approach and the type of bibliographic research are used. The Charter of 1988, in its preamble, presents "equality and justice as the supreme value of a fraternal, pluralist and unprejudiced society," aims sought by the constituents for the Democratic Rule of Law. Eligio Resta's book "The Right Fraternal" emphasizes that this direct lives on the lack of fundamentals, because the truth that moves it is an inclusive right, which promotes access to fundamental rights and assets bet on the existence of a common good. The purpose of the action to receive immigrants, a palliative measure of the Federal Government, that only the state of Rio Grande do Sul received approximately 602 Venezuelans for shelter compact with this vision. In partnership with UNHCR, Venezuelans receive housing, food and basic services. We can see initiatives that can be concluded as praxis of Fraternal Law; there is still much to be done.
\end{abstract}

Keywords: fraternal law; public policy; host; venezuelans.

\title{
1. Introdução
}

Como consequência da crise econômica, política e social na Venezuela, gerou-se um grande fluxo migratório de venezuelanos adentrando o Brasil pela cidade de Boa Vista (RR). O Governo Federal em parceria com organizações internacionais necessitou estabelecer políticas públicas paliativas para prestar suporte a esses imigrantes, tendo em vista a sobrecarga nos sistemas de saúde e assistência social na região fronteiriça. Uma dessas políticas foi a criação de um processo de interiorização que têm por finalidade fornecer suporte e qualidade de vida aos imigrantes venezuelanos, garantindo assim sua dignidade humana. $\mathrm{O}$ presente artigo consiste em analisar se as políticas públicas de acolhimento dos venezuelanos no Rio Grande do Sul podem ser analisadas sob a teoria do Direito Fraterno.

Por conseguinte, este artigo está subdividido em cinco partes: a primeira trata-se do fluxo migratório e a crise venezuelana, abordando o direito de migrar e principais fatores que levaram ao processo migratório dos venezuelanos. O segundo discorre sobre a proteção constitucional versus o plano de interiorização migratória, relatando os dispositivos legais que resguardam os direitos do migrante e a ação governamental denominada processo de interiorização que tem por finalidade proporcionar ao imigrante venezuelano um novo recomeço de vida. A terceira refere-se ao processo de interiorização no RS, apresenta como está sendo realizado o acolhimento dos imigrantes que chegaram ao estado. A quarta parte apresenta o paradigma do Direito Fraterno frente ao fenômeno, observando se as políticas públicas do Governo Federal podem ser analisadas sob a teoria do direito fraterno. E por ultimo está a conclusão que tem por finalidade verificar se os objetivos do trabalho foram atingidos e expor o resultado da presente pesquisa. 
Como metodologia aplicada, utilizou-se do método dedutivo, tendo em vista a grande quantidade de notícias a respeito do tema estudado e o tipo de pesquisa bibliográfico. Pesquisa essa que considerou bibliografias que abordam o tema do direito fraterno além de notícias e discussões nos principais meios de comunicação a cerca da crise venezuelana e políticas públicas adotadas pelo Governo Federal para acolhimento dos imigrantes que chegaram ao Rio Grande do Sul através do processo de interiorização.

\section{Fluxo migratório e a crise venezuelana}

A migração é um direito inerente à pessoa humana, garantido a toda e qualquer pessoa nos termos da Declaração Universal dos Direitos Humanos de 1948, especificamente no artigo 13 que versa: "Todo ser humano tem o direito de deixar qualquer país, inclusive o próprio, e a este regressar.".

De acordo com dados disponibilizados pelo Alto Comissionado da ONU para Refugiados (ACNUR), até 2018, cerca de 68,5 milhões de pessoas em todo o mundo foram forçadas a sair de suas casas, sendo que entre elas aproximadamente 25,4 milhões são refugiados e mais da metade desses são menores de 18 anos. Dentre os motivos que intensificam e elevam os fluxos migratórios a estes números estão o aumento de conflitos internos e crise econômicas ao redor do mundo.

A Venezuela, atualmente, sofre de uma grande depressão econômica, política e social. A instabilidade no país começou após a morte do ex-presidente Hugo Chávez em 2013, momento em que o preço do barril de petróleo, principal produto de exportação do país, entrou em queda. Segundo o jesuíta venezuelano Pedro Trigo, Chávez acreditava que a renda petrolífera pudesse substituir o trabalho produtivo. Como consequência da queda da principal fonte de renda do país, o sucessor presidencial eleito na Venezuela, Nicolás Maduro, veio a comandar o país em meio à instabilidade, crise política e econômica, miséria e escassez de mantimentos e serviços essenciais, inflação, acusações de arbitrariedades e violências.

Em meio a este cenário, milhares de venezuelanos foram obrigados a deixar seu país natal em busca de uma melhor qualidade de vida, pois a instabilidade do país teve influência extrema sobre a população, afetando o fornecimento de itens básicos e de grande importância como alimentação, produtos de higiene pessoal, medicamentos, entre outros. Além da falta de produtos básicos, serviços essenciais prestados pelo poder público também se encontram em carência, como por exemplo saúde e segurança. Segundo pesquisa realizada pelo ACNUR o número de refugiados e migrantes venezuelanos chega a 3 milhões, onde cerca de 2,4 milhões 
estão abrigados nos países da América Latina e Caribe, em especial no Caribe, sendo que o Brasil, até o ano de 2018 recebeu aproximadamente 85 mil venezuelanos.

Tendo isso em vista, o Governo Federal brasileiro precisou estabelecer políticas paliativas como resposta humanitária ao processo migratório oriundo da crise da Venezuela, com o intuito de acolher os venezuelanos imigrantes, buscando garantir-lhes acesso à inserção social e econômica de forma igualitária como forma de salvaguardar a dignidade da pessoa humana.

\section{A proteção constitucional versus o plano de interiorização migratória}

A Constituição Federal de 1988 em seu preâmbulo elenca "a igualdade e justiça como o valor supremo de uma sociedade fraterna, pluralista e sem preconceitos" como um dos desígnios almejados pelos constituintes para o Estado Democrático de Direito. Observa-se que o princípio desse desígnios consta no caput do art. $5^{\circ}$ da $\mathrm{CF} / 88$ que versa sobre os direitos e garantias fundamentais, validando aos "brasileiros e estrangeiros residentes no País" direito à vida, à liberdade, à igualdade, à segurança e à propriedade.

Ainda, com o intuito de garantir equidade aos estrangeiros no País e regular as políticas de acolhimento, a Lei 13.445/2017, que dispõe sobre a migração, elenca direitos e deveres do migrante e visitante, estabelecendo princípios e diretrizes para as políticas públicas que devem ser adotadas pelo Brasil. Dentre os artigos presentes nessa lei, está o art. $4^{\circ}$ que se refere aos princípios e garantias do migrante em território nacional, garantindo-lhes "condição de igualdade com os nacionais, a inviolabilidade do direito à vida, à liberdade, à segurança e à propriedade", também assegurado "direitos e liberdade civil, social, cultural e econômica, a liberdade de circulação em território nacional, acesso a serviços públicos de saúde, assistência social, à previdência social e à educação pública, nos termos da lei, sem discriminação em razão da nacionalidade e da condição migratória".

Por meio do ordenamento jurídico pátrio e como medida urgente para o acolhimento dos venezuelanos imigrantes no Brasil, refugiados em razão da crise em seu país de origem, o Governo Federal vêm realizando ações de caráter emergencial com a finalidade de assegurar os direitos dos migrantes garantidos em lei. Como principal medida encontra-se a criação do Comitê Federal de Assistência Emergencial, grupo coordenado pela Casa Civil com a finalidade de definir ações para o acolhimento dos imigrantes. Dentre essas medidas consta a instalação de uma sala de situação no Ministério da Defesa para monitorar as demandas em Boa Vista (RR) e na cidade fronteiriça de Pacaraima, principal ponto de entrada dos venezuelanos. 
As linhas de atuação do governo têm como objetivo o ordenamento de fronteira, a interiorização, o censo do imigrante e o centro de triagem e apoio aos venezuelanos. A Polícia Federal está a cargo do registro dos venezuelanos que entraram no país, compreendendo desde o perfil desses imigrantes e o deslocamento para outros estados com a finalidade de lhes fornecer recolocação laboral. Os venezuelanos estão recebendo assistência médica e vacinação imediata, um dos requisitos definidos para a liberação desse translado a outro estado e para a vaga de trabalho.

A ação governamental que realiza o translado dos imigrantes a outros estados brasileiros denomina-se de processo de interiorização e está sendo coordenada pelo Ministério da Justiça em parceria com o Ministério do Desenvolvimento Social (MDS) e ACNUR, sendo estes os responsáveis por encontrar abrigo aos venezuelanos nas cidades destino. "É uma crise humanitária que nós não podemos virar as costas e estamos fazendo o possível para atender da melhor maneira", declarou o Ministro-Chefe da Casa Civil, Eliseu Padilha em entrevista coletiva no dia 22 de fevereiro de 2018.

\section{O processo de interiorização no $R S$}

O processo de interiorização do Governo Federal levou aproximadamente 2.500 venezuelanos da fronteira de Roraima a oito estados do país e o Distrito Federal. Entre esses estados está o Rio Grande do Sul que recebeu mais de 840 imigrantes, distribuídos nas cidades de Cachoeirinha, Canoas, Chapada, Esteio, Porto Alegre, Santo Antônio da Patrulha e Viamão. A fim de ajudar no custeio desses imigrantes, o Ministério do Desenvolvimento Social está repassando aos abrigos e prefeitura cerca de $\mathrm{R} \$ 400,00$ reais por mês para cada venezuelano acolhido. O processo de interiorização também conta com o apoio do ACNUR, da Organização Internacional para as Migrações (OIM), do Fundo de População das Nações Unidas (UNFPA) e do Programa das Nações Unidas para o Desenvolvimento (Pnud).

Na cidade de Canoas, todos os venezuelanos abrigados já possuem cartão de saúde e receberam reforço da vacinação. Já em Esteio, as famílias começaram a desenvolver sua inserção social, visto que as crianças até mesmo já estão sendo matriculadas nas escolas do município. $\mathrm{Na}$ maioria das cidades os alojamentos estão sendo custeados pela ONU (Organização das Nações Unidas) e a alimentação está sendo custeada pelo Governo Federal e distribuída pelo Exército.

De acordo com Alberto Beltrame, gaúcho e ministro do Desenvolvimento Social, "Muitos antepassados vieram fugindo de guerras, pobreza e fome. Além disso, a bandeira do estado tem o lema humildade, liberdade e igualdade. A humanidade fala mais alto e o povo 
gaúcho está demonstrando isso”, atribuindo a liderança na recepção dos refugiados ao perfil de formação étnica do Rio Grande do Sul.

Segundo relato de venezuelanos que chegaram ao estado, percebemos a expectativa de um novo recomeçar de vida. Em muitos depoimentos nota-se que o sentimento de tristeza por abandonar seu país é muito forte, porém a busca por mais oportunidades, emprego e qualidade de vida falam mais alto. "Eu quero para minhas filhas um futuro diferente do que eu tive, com mais oportunidades e que nunca precise deixar seu país para sobreviver" destaca um dos imigrantes interiorizados.

A fim de proporcionar esse "recomeçar de vida" com uma melhor qualidade aos imigrantes, o Ministério de Desenvolvimento Social através da coordenação da Secretaria Nacional de Assistência Social promoveu um seminário aos Gestores da Assistência Social dos municípios que demonstraram interesse em receber venezuelanos, com o objetivo de discutir a forma como os municípios podem participar do processo de interiorização.

A interiorização ultrapassa apenas o acolhimento aos imigrantes, preparo dos abrigos, mobilização da comunidade e poder público e o trabalho realizado pela rede socioassistencial do Sistema Único de Assistência Social (Suas). São nos Centros de Referência de Assistência Social (Cras) que os novos moradores fazem o registro no Cadastro Único para Programas Sociais do Governo Federal para acesso aos serviços oferecidos pela Assistência Social.

A cidade de Santo Antônio da Patrulha, que atualmente abriga cerca de 40 venezuelanos, estava entre uma das cidades que participaram do seminário oportunizado pelo Ministério do Desenvolvimento Social, segundo a secretária do Trabalho e do Desenvolvimento Social do município, Ana Cristina Cardoso, o seminário serviu para ajudar na adaptação dos imigrantes à nova vida. "Sou de uma cidade pequena e pude sanar várias dúvidas quanto a integrar essa população à nossa cidade. Ouvir outras experiências que já efetivaram este acolhimento foi essencial para iniciarmos o processo o quanto antes", afirmou ela.

O processo de interiorização trará benefícios não somente aos venezuelanos destaca o oficial de Meios de Vidas do ACNUR no Brasil em entrevista para o Ministério de Desenvolvimento Social. Para ele a ação "além de reduzir a pressão sobre os serviços públicos de Roraima, que foram afetados pelo aumento repentino da demanda, a chegada dos venezuelanos deve contribuir para o desenvolvimento da região que os acolhe, tendo em vista que a maioria possui boa formação, e alguns até pós-graduação”.

\section{O paradigma do Direito Fraterno frente ao fenômeno}


As avassaladoras modificações socioeconômicas experimentadas pela sociedade mundial nos últimos anos, tem trazido reflexos sobre a realidade jurídica, impactando o ordenamento positivo e, por via de consequência se transformam em subsídios empíricos que afligem os juristas e estudiosos do Direito.

O sistema jurídico não serve unicamente para se autolegitimar, "Sua função está em se projetar eficazmente além muros, para provocar intervenções pontuais e cirúrgicas sobre as necessidades de um povo de um determinado contexto, com determinados valores, dentro de seus anseios e perspectivas" (BITTAR, 2009, p. 212). Pois, não adianta existir um conjunto de leis sustentado por fundamentos ideológicos, mas ineficiente para responder aos mais simples pleitos das pessoas ao qual se destinam e as emergentes demandas sociais contemporâneas (BITTAR, 2009, p. 213).

Afirma Bittar (2009, p. 213) que a sociedade moderna abriu espaço para os "estranhos", os quais importunam o cenário dos que persistem em olhar apenas a "homogeneidade dos iguais diante de si":

As lutas morais mais gigantescas da pós- modernidade giram em torno da presença de excluídos no mapa da humanidade, excluídos de toda sorte, que pululam em meio às ruas das grandes metrópoles, que se aglomeram em verdadeiras cidadelas independentes que são as favelas, que buscam asilo em países estrangeiros, que atravessam perigosamente fronteiras em busca de socorro em face dos flagelos da guerra etc. [sic]

Os "estranhos" refere-se as pessoas procedentes do crescente e intenso fluxo migratório que nos últimos anos tem afetado não somente as grandes pujanças mundiais da Europa e da América do Norte, mas inúmeros outros países que estão em desenvolvimento e com potenciais avanços econômicos, tais como os países da América Latina a exemplo do Brasil e do Chile.

Face ao apresentado, aparece a exigência da edificação de marcos e a afirmação de novos paradigmas junto ao sistema jurídico, que sejam eficazes em formar diretrizes para a atuação estatal, a fim de dar conta das emergentes demandas decorrentes dos processos humanos, frente as mazelas ocasionadas pelas relações econômicas e sociais, eis que o Direito encontra-se desafiado para reger as relações entre os sujeitos entre si e entre estes e o Estado, da mesma forma que entre os próprios Estados.

Ao prefaciar a obra "O Direito Fraterno", de Eligio Resta, traduzida ao português, GRAU (2004, p. 7) observa que usualmente, o Direito tem sido considerado como uma "linguagem do social", mas em seus ensinamentos ressalta que "o direito deve ser uma linguagem da humanidade", uma vez que, para que se constitua um tempo mais justo, faz-se necessário um ambiente politicamente aberto e ilimitado, para que se desenvolvam as bases 
de um Direito Fraterno e torne possível a constituição de uma vivência comunitária, no sentido de comum-unidade, de direitos equitativos.

O Direito consiste em uma “[...] construção, um artefato humano fruto da política que produz o Direito Positivo. Requer a razão para pensar, projetar e ir transformando este artefato em função das necessidades da convivência coletiva”, é o que sintetiza LAFER (2004, p. VIII) a respeito do pensamento de Norberto Bobbio.

Acrescenta VIAL (2004, p. 73) que o Direito Fraterno, tem como principal pressuposto a realidade, motivo pelo qual, trata-se de uma abordagem científica que opera uma nova configuração de análise do direito contemporâneo, propondo uma "[...] reestruturação de todas as políticas públicas que pretendam uma inclusão de fato universal.”

Nesse contexto, o Direito Fraterno constitui-se como um paradigma para a compreensão e mais ainda a aplicação de políticas públicas frente às fatos e demandas emergentes que o desafio migratório impõe, haja vista que pode este direito ser concebido como o meio mediante o qual pode desenvolver um processo de auto responsabilização: "Trata-se, enfim, de um modelo de Direito que abandona o confim fechado da cidadania e olha para a forma nova de cosmopolitismo, que não são os mercados, mas a obrigatoriedade universalista de respeitar os Direitos Humanos [...]” (RESTA, 2004, p. 13-14).

Anacronicamente, o Direito Fraterno consiste em uma aposta, com uma perspectiva distinta que vai além da forma estatal das pertenças fechadas, conduzidas por uma lógica ambígua que compreende alguns cidadãos, excluindo outros.

Destarte, o empenho está em colocar a aflição das fronteiras estatais de forma a acender espaço para abordar os Direitos Humanos, com a consciência: “[...] de que a humanidade é simplesmente o lugar comum, somente em cujo interior pode-se pensar o reconhecimento e a tutela" (RESTA, 2004, p. 15).

Dessa forma o Direito Fraterno pode ser considerado como o embasamento político jurídico face às medidas adotadas pelo Governo Federal para as ações de interiorização dos imigrantes venezuelanos aos demais estados-membros brasileiros.

\section{Conclusões}

Diante de uma das maiores crises migratórias da América Latina, a crise da Venezuela, milhares de pessoas tiveram de deixar seu país natal em busca de qualidade de vida e acesso a produtos básicos como, por exemplo, alimentação e saúde. O presente trabalho buscou analisar se a política pública de acolhimento dos imigrantes venezuelanos no estado do Rio Grande do Sul pode ser analisada sob a teoria do Direito Fraterno. 
O estudo demonstrou ser de extrema relevância, pois trata-se de direito humano garantido e resguardado na Declaração Universal dos Direitos Humanos de 1948, o Direito de Migrar. Esse direito, por sua vez, não deve ser negligenciado pela população brasileira e principalmente pelo país e organizações mundiais voltadas ao tema.

Desta forma, a pesquisa realizada demonstrou que as políticas públicas do Governo Federal, com propósito de inclusão aos imigrantes venezuelanos no estado do Rio Grande do Sul, podem ser concluídas como práxis ao direito fraterno, pois garantem uma igualdade aos venezuelanos frente à população brasileira, afirmando-lhes, além de uma inserção social e econômica, os mesmos acessos à educação, à saúde, à assistência social e previdência social prestados aos brasileiros. Contudo, notório que ainda há muito a ser estruturado.

\section{Referências}

A Venezuela chegou ao fundo do poço. É preciso uma democracia real. Entrevista especial com Pedro Trigo. Disponível em: http://www.ihu.unisinos.br/582321-a-venezuela-chegou-aofundo-do-poco-e-preciso-de-uma-democracia-real-entrevista-especial-com-pedro-trigo. Acesso em: 03 janeiro 2019.

Agência da ONU para Refugiados. Disponível em: https://www.acnur.org/portugues/dadossobre-refugio/. Acesso em: 03 janeiro 2019.

BITTAR, Eduardo Carlos Bianca. O direito na pós-modernidade (e reflexões frankfurtianas). 2. ed. rev. atual. amp. Rio de Janeiro: Forense, 2009.

BRASIL. Lei ${ }^{\circ}$ 13.445, de 24 de maio de 2017. Institui a Lei de Migração. Disponível em: http://www.planalto.gov.br/ccivil_03/_Ato2015-2018/2017/Lei/L13445.htm. Acesso em: 04 janeiro 2019.

Chegada de venezuelanos ao Rio Grande do Sul completa um mês. Disponível em: https://g1.globo.com/rs/rio-grande-do-sul/noticia/2018/10/05/chegada-de-venezuelanos-norio-grande-do-sul-completa-um-mes.ghtml. Acesso em: 04 janeiro 2019.

Constituição (1988). Constituição da República Federativa do Brasil. Brasília, DF: Senado Federal: Centro Gráfico, 1988. 292 p. BRASIL.

Entenda a real dimensão da crise da Venezuela, do petróleo à fome. Disponível em: https://noticias.r7.com/internacional/entenda-a-real-dimensao-da-crise-da-venezuela-dopetroleo-a-fome-18052018. Acesso em: 03 janeiro 2019. 
Governo define ações para acolhimento de imigrantes venezuelanos. Disponível em: http://www.casacivil.gov.br/central-de-conteudos/noticias/2018/fevereiro/governo-defineacoes-para-acolhimento-de-imigrantes-venezuelanos. Acesso em: 04 janeiro 2019.

GRAU, Eros Roberto. Prefácio. In: RESTA, Eligio. O Direito Fraterno.

Tradução de Sandra Regina Martini Vial. Santa Cruz do Sul: EDUNISC, 2004.

Interiorização encaminha 230 venezuelanos ao Rio Grande do Sul e Paraná. Disponível em: http://mds.gov.br/area-de-imprensa/noticias/2018/setembro/interiorizacao-encaminha-230venezuelanos-ao-rio-grande-do-sul-e-parana. Acesso em: 10 janeiro 2019.

LAFER, Celso. Apresentação. In: BOBBIO, Norberto. A era dos direitos. Tradução de Carlos Nelson Coutinho. 18. tir. nova ed. Rio de Janeiro: Elsevier, 2004.

Mais 377 venezuelanos são transferidos para o Rio Grande do Sul. Disponível em: http://mds.gov.br/area-de-imprensa/noticias/2018/setembro/mais-377-venezuelanos-saotransferidos-para-o-rio-grande-do-sul. Acesso em: 10 janeiro 2019.

Migrações Venezuelanas /Rosana Baeninger; João Carlos Jaroshinski Silva (Coordenadores); Catarina Von Zuben; Paolo Parise; José Carlos Pereira; Francisco Max; Luís Felipe A. Magalhães, Daniel Menezes; Duval Fernandes; Alberto Jakob; Luis Renato Vedovato; Camila R. da Silva; Natália Demétrio; Joice Domeniconi; Victor Del Vecchio; (Organizadores). Campinas, SP: Núcleo de Estudos de População "Elza Berquó" - Nepo/Unicamp, 2018. 400 p.

Número de refugiados e migrantes venezuelanos chega a 3 milhões. Disponível em: https://www.acnur.org/portugues/2018/11/09/numero-de-refugiados-e-migrantesvenezuelanos-chega-a-3-milhoes/. Acesso em: 03 janeiro 2019.

RESTA, Eligio. O Direito Fraterno. Tradução de Sandra Regina Martini Vial. Santa Cruz do Sul (RS): EDUNISC, 2004.

Rio Grande do Sul recebe maior número de refugiados venezuelanos no. Disponível em: https://www.jornaldocomercio.com/_conteudo/geral/2018/09/647628-rio-grande-do-sullidera-recepcao-a-refugiados-venezuelanos-o-brasil.html. Acesso em: 04 janeiro 2019.

Seminário sensibiliza gestores municipais a receberem imigrantes venezuelanos. Disponível em: $\quad$ http://mds.gov.br/area-de-imprensa/noticias/2018/novembro/seminario-sensibilizagestores-municipais-a-receberem-imigrantes-venezuelanos. Acesso em: 10 janeiro 2019. 
Venezuelanos são recebidos com festa em Chapada, no norte do RS. Disponível em: https://gauchazh.clicrbs.com.br/geral/noticia/2018/09/venezuelanos-sao-recebidos-com-festaem-chapada-no-norte-do-rs-cjmm61hvr00n901rx1moyl9ey.html. Acesso em: 04 janeiro 2019.

VIAL, Sandra Regina Martini. Direito Fraterno. In: Estudo \& Debate. Lageado/RS, v. 11, n. 1, p. 71-80, 2004. 